\title{
OBITUARI: CRISTIÁN CARANDELL (1952-2019)
}

\author{
XAVIER ESPLUGA \\ Universitat de Barcelona \\ xespluga@ub.edu \\ ORCID: 0000-0002-6690-1974
}

El nom de Cristián Carandell Robusté (1952-2019), nascut a Reus i traspassat a Sitges poc abans del dia de Nadal, no era excessivament conegut més enllà del cercle d'especialistes en literatura neohel-lènica i en comèdia àtica; i, tanmateix, Carandell portava a l'esquena una perllongada activitat docent -la seva principal ocupació laborali un bon grapat de traduccions del grec, antic i modern, que el fan mereixedor d'un record necessari.

Darrer dels set fills de Joan Carandell i Marimón, tot un "senyor de Barcelona" que l'any 1982 guanyà el premi Victor Català amb el relat Quaranta històries (amb el pseudònim Llorenç Sant Marc), ${ }^{1}$ Cristián Carandell s'havia llicenciat en Filologia Clàssica per la Universitat de Barcelona l'any 1979. Havia presentat una tesina sobre l'obra poètica d'Andreas Kalvos (1792-1869), dirigida per Carles Miralles, que assenyalava ja els seus interessos per la literatura neohel-lènica, concretats poc després. En efecte, l'any següent, ${ }^{2}$ Carandell girava al castellà la seva primera traducció, ${ }^{3}$ To

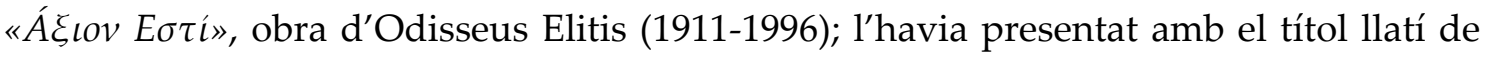
"Dignum est", el qual intentava de recuperar la solemnitat de la fórmula de lloança, pròpia de la litúrgia ortodoxa, del títol grec original, tal com el traductor mateix explicava en una nota. ${ }^{4}$ L'obra sortia a la col-lecció "Selecciones de poesia universal" de Plaza y Janés perquè el poeta grec acabava de guanyar el premi Nobel de Literatura del 1979. Posteriorment aquesta obra d'Elitis seria traduïda al català per Rubén Montañés, ${ }^{5}$ que en mantingué el títol grec original, mentre que Carandell n'edità més endavant una

${ }^{1}$ Per a una semblança de Carandell pare, vegeu la pàgina que li ha dedicat la biblioteca de la Universitat Autònoma de Barcelona, entitat dipositària dels seus fons, a l'adreça: https://www.bib.uab.cat/socials/carandell/biografia.html.

2 Tot i que de vegades es dona 1979 per a aquesta obra, el meu exemplar, corresponent a la primera edició, porta la data de "Marzo, 1980".

${ }^{3}$ Carandell (1980).

${ }^{4}$ Carandell (1980: 137): “El título original 'Axion esti' es una fórmula de alabanza que procede de un himno bizantino a la Virgen. Su correspondiente latino, 'Dignum est', si bien no conserva la actualidad de la fórmula griega, parece más conveniente que la traducción castellana 'Es digno', que sencillamente no es una fórmula de alabanza. Ahora bien, en la tercera parte, 'El gloria', el poeta hace repetido uso de esta fórmula. En este caso, 'Dignum est' sonaba hueco y artificioso, por lo que he recurrido a una fórmula castellana: Loado sea".

${ }^{5}$ Vegeu Montañés (1992). Per a les traduccions catalanes d’Elitis, vegeu Gestí (2004), p. 172. 
versió bilingüe grec-castellà, mantenint el títol llatí. ${ }^{6}$ Aquell mateix any de 1980, Carandell publicava l'article "Odisseas Elytis y sus versos", un recull de traduccions que complementava un article del doctor Alsina sobre la lírica neogrega contemporània ${ }^{7} \mathrm{i}$ que va aparèixer al primer número de la Revista de Occidente d'aquella anyada. ${ }^{8}$ No em consta que acabessin apareixent les obres d'altres escriptors neogrecs en les quals estava

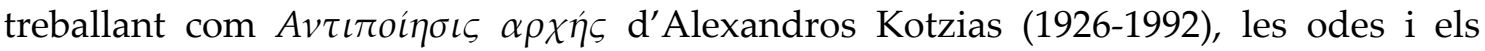
poemes lírics de Kalvos, que havia estudiat per a la memòria de llicenciatura, o una antologia poètica de Takis Varvitsiotis (1916-2011); ${ }^{9}$ totes aquestes iniciatives, emperò, ja denoten la pluralitat del seus interessos i l'abast de les seves lectures.

Bona part de l'activitat laboral de Carandell, com a professor de llatí i de grec, se centrà a l'Institut Joan Ramon Benaprès de Sitges, al Garraf, comarca on s'havia instal-lat i residia. Les seves preocupacions propedèutiques traspuen en dues de les seves obres que constitueixen adaptacions castellanes de textos clàssics. En primer lloc, el seu Sócrates según Platón, del 1984, publicada per l'Editorial Casals, que consistia en una selecció de passatges de l'obra platònica al-lusius a la figura del mestre; ${ }^{10}$ més endavant, el 2001, per a Maeva Ediciones, publicà una adaptació del llibre II de les Històries d'Heròdot, amb el títol Egipto, el don del Nilo, ${ }^{11}$ sempre en un estil amè i comprensible.

En els darrers anys Carandell ha estat més conegut i reconegut, principalment perquè l'editorial Adesiara li (re)publicà diverses traduccions d'Aristòfanes: Lísístrata (2010), Les granotes (2014) i Els acarnesos (2017). ${ }^{12}$ Tanmateix, però, amb anterioritat, a la menys coneguda "Col-lecció popular de teatre clàssic universal" de l'Institut del Teatre -de la qual era director el seu germà Josep Maria (†2003)-Carandell ja havia girat al català la Lisístrata (1988), La pau (2000) i Els ocells (2002). La primera obra meresqué el premi Josep Maria de Sagarra en l'edició del 1987, ${ }^{13}$ un guardó que es concedia a textos dramàtics en català o a traduccions inèdites de textos teatrals d'altres llengües al català.

Té raó Jaume Almirall en assenyalar com a "rara qualitat" de les traduccions aristofàniques de Carandell el fet que "es poden llegir"; 14 les seves versions, molt entenedores, aconsegueixen de mantenir la gràcia i comicitat de l'original, circumstància difícil atesa l'àmplia diferència cultural que separa els valors del nostre món actual dels de l'Atenes del segle V, una societat que Pierre Vidal-Naquet havia definit com un "club

${ }^{6}$ Fou republicada amb l'afegit d'altres poemes del poeta grec i un nou pròleg l'any 2008 a Círculo de Lectores. Vegeu Carandell (2008).

${ }^{7}$ Alsina Clota (1980).

8 Carandell (1980).

9 Prenc aquestes notícies d'una nota d'Araceli Alba, publicada al número 45 del 1988 a la revista local "Montgròs" de Sant Pere de Ribes arran de la concessió del premi Josep Maria de Sagarra i que fou republicada a la revista "L'altaveu de Ribes", en el número 8 del 2005. Vegeu Alba (2005).

10 Carandell (1984).

${ }^{11}$ Carandell (2001).

12 Carandell (2010); Carandell (2014); Carandell (2017), respectivament.

${ }^{13}$ En aquella edició el premi -inclòs entre els Premis Nacionals de Teatre i Dansa- era convocat conjuntament per la Generalitat de Catalunya i la Diputació de Barcelona, i gestionat a través de l'Institut del Teatre.

${ }^{14}$ Almirall (2020). 
d'hommes" ${ }^{15}$ Sense desmerèixer les traduccions aristofàniques de mossèn Balasch per a la Fundació Bernat Metge (1969-1974) ${ }^{16}$ i alguna altra versió puntual per a altres col-leccions més divulgatives -Les vespes de Josep Antoni Clua (1991) i (2017), ${ }^{17}$ Els núvols de Mercè Valls (1994), ${ }^{18}$ la Lisístrata de Joan Pagès (2004), ${ }^{19}$ o Els ocells de Carme Llitjós $(2008)^{20}-$, Carandell havia reeixit a recrear la vis comica original i preservar amb prou eficàcia el que segons Quintilià era "illam solis concessam Atticis uenerem". ${ }^{21}$ Tot això feia que el text resultant fos especialment adequat per a l'adaptació escènica, cosa que s'esdevingué puntualment en més d'una ocasió. És una llàstima, doncs, que la "vella dama" ens hagi privat, abans d'hora, de poder gaudir de més Aristòfanes de Carandell, ara que s'havia jubilat, posats en aquell seu "català creïble, ric i expressiu", 22 que ensems apareix "de vegades tan vulgar com ho exigeix l'original grec". ${ }^{23}$

\section{BIBLIOGRAFIA}

AlBA, Araceli (2005). “El premi Josep Maria de Sagarra”, L'altaveu de Ribes, n. 8, 2005, p. 19.

AlmiRAll, Jaume (2020). "En la mort de Cristián Carandell". Nuvol. El digital de cultura, 19.1.2020 [disponible a https://www.nuvol.com/llibres/en-la-mort-de-cristiancarandell-78312] <<consulta del 11 de febrer de 2020 > .

BALASCH, Manuel (1969-1974). Aristòfanes. Comèdies. Text revisat i traducció de M. Balasch, Barcelona, Fundació Bernat Metge, 1969-1974 [en 6 volums].

CARANDELL, Cristián (1979). La obra poética de Andreas Kalvos: Traducción y comentario. Memoria de Licenciatura presentada por Cristián Carandell Robusté. Director ponente Carles Miralles Solà, Barcelona, Universitat de Barcelona, 1979.

CARANDell, Cristián (1980). Odisséas Elýtis. Dignum est. Versión de Cristián Carandell, Barcelona, Plaza y Janés.

CARANDELL, Cristián (1980). “Odisseas Elytis y sus versos”, Revista de Occidente, año 1, 1980, pp. 163-174.

CARANDELL, Cristián (1984). Sócrates según Platón, Barcelona, Casals, 1984.

${ }^{15}$ La definició, que reflecteix els marcs mentals i interpretatius del segle $X X$, fou formulada per Vidal-Naquet (1981: 81), tot i que expressions semblants es troben obres d'autors anteriors que insisteixen en l'exclusió de les dones (i d'altres col-lectius) de l'espai social de participació pública.

${ }^{16}$ Balasch (1969-1974).

${ }_{17}$ Publicades originalment a l'efímera col-lecció "La Quimera" de la desapareguda Editorial Irina -Clua (1991)-, Les Vespes han tornat a aparèixer a la col-lecció Polyeidia de la Universitat de Lleida. Vegeu Clua (2017).

18 Valls i Bosch (1994).

19 Pagès (2004).

${ }^{20}$ Llitjós (2008).

${ }^{21}$ Quint. inst. or. 10.1.100.

${ }^{22}$ Almirall (2020).

${ }^{23}$ Llovet (2017). 
CARANDELL, Cristián (19881; 19932). Aristòfanes. Lisístrata. Traducció i pròleg de Cristián Carandell, Barcelona, Institut del Teatre - Diputació de Barcelona, 19881; 1993² (Col-lecció popular de teatre clàssic universal, 32).

CARAndell, Cristián (2000). Aristòfanes. La Pau. Traducció de Cristián Carandell, Barcelona, Institut del Teatre, - Diputació de Barcelona, 2000 (Col-lecció popular de teatre clàssic universal, 58).

CARANDell, Cristián (2001). Heródoto. Egipto, el don del Nilo, Madrid, Maeva Ediciones, 2001.

CARANDELL, Cristián (2002). Aristòfanes. Els ocells. Traducció de Cristián Carandell, Barcelona, Institut del Teatre, - Diputació de Barcelona, 2002 (Col-lecció popular de teatre clàssic universal, 60).

CARANDELl, Cristián (2008). Odisséas Elýtis. Dignum est y otros poemas. Traducción, selección y prólogo de Cristián Carandell, Barcelona, Galaxia Gutenberg - Círculo de Lectores, 2008.

CARANDell, Cristián (2010). Aristòfanes. Lisístrata. Traducció de Cristián Carandell, Barcelona, Adesiara, 2010 (Aetas 8).

CARANDELL, Cristián (2014). Aristòfanes. Les granotes. Traducció de Cristián Carandell, Barcelona, Adesiara, 2014 (Aetas, 22).

CARANDELL, Cristián (2017). Aristòfanes. Els acarnesos. Traducció de Cristián Carandell, Barcelona, Adesiara, 2017 (Aetas, 29).

Clota Alsina, Josep (1980). “La lírica contemporánea”, Revista de Occidente 1, 1980, pp. 147-162.

ClUA, Josep Antoni (1991). Aristòfanes. Les vespes. Introducció, traducció i notes de Josep Antoni Clua i Serena, Barcelona, Irina, 1991 (La Quimera, 9)

CluA, Josep Antoni (2017). Aristòfanes. Les vespes. Introducció, traducció i notes de Josep Antoni Clua i Serena, Lleida, Edicions de la Universitat de Lleida, 2017 (Polyeideia). 7.

DE SAGARRA, Joan (2006). “Los Carandell”, La Vanguardia. Vivir, 9 d'abril de 2006, p.

GESTÍ, Joaquim (2004). “Traduccions catalanes de literatura neogrega (1881-2003)”, Quaderns. Revista de traducció 11, 2004, pp. 159-174.

Llitjós I PASCUAL, Carme (2008). Aristòfanes, Els Occells. Introducció, guia didàctica $i$ traducció a càrrec de Carme Llitjós i Pascual, s.l., Prósopon. Festivales de Teatro GrecoLatino, 2008 (Textos de Teatro Grecolatino).

LlOVET, Jordi (2017). “Vinga comèdia!”, Ara. Ara Llegim, 9 setembre 2017, p. 45.

MONTAÑÉS, Rubén Josep (1992). Odisseus Elytis. To «Axion Estí». Traducció, notícia preliminar i notes de Rubén Josep Montañés Gómez, València, Edicions Alfons el Magnànim, 1992.

PAGÈS, Joan (2004). Aristòfanes. Lisístrata. Introducció, traducció i notes de Joan Pagès, Barcelona, La Magrana, 2004 (L'Esparver clàssic, 53)

VALLS I BOSCH, Mercè (1994). Aristòfanes. Els núvols. Introducció, traducció i notes de Mercè Valls i Bosch, Barcelona, La Magrana, 1994 (L'Esparver clàssic, 6).

VIDAL-NAQUET, Pierre (1981). Le chasseur noir. Formes de pensée et formes de société dans le monde grec, Paris, Maspero, 1981. 